Bulletin d'Histoire Contemporaine de l'Espagne

$51 \mid 2017$

Les forces politiques durant la Seconde République espagnole

\title{
Paul Preston, El final de la Guerra civil. La ultima
} puñalada a la República

Julián Vadillo Muñoz

\section{(2) OpenEdition \\ Journals}

Edición electrónica

URL: http://journals.openedition.org/bhce/805

DOI: 10.4000/bhce.805

ISSN: 1968-3723

\section{Editor}

Presses Universitaires de Provence

Edición impresa

Fecha de publicación: 1 junio 2017

Paginación: 340-342

ISSN: 0987-4135

\section{Referencia electrónica}

Julián Vadillo Muñoz, «Paul Preston, El final de la Guerra civil. La ultima puñalada a la República », Bulletin d'Histoire Contemporaine de l'Espagne [En línea], 51 | 2017, Publicado el 09 octubre 2018, consultado el 23 septiembre 2020. URL : http://journals.openedition.org/bhce/805 ; DOI : https://doi.org/10.4000/ bhce.805 
El golpe de Estado contra la República del 17-18 de julio de 1936 fue la causa del estallido de la Guerra civil. Casi tres años de batallas y combates que finalizaron con la victoria de los golpistas y la imposición de una dictadura personificada en Francisco Franco que no tuvo piedad con los vencidos. La derrota de la República se debió después a distintos factores, unos con más peso que otros. Analizar las últimas semanas del conflicto, es acercarse a alguno de esos otros factores. Quizá no el principal, pero sí subsidiario y con suficiente peso como para merecer la atención de diversos historiadores.

Recientemente el catedrático de historia contemporánea de la Universidad Carlos III de Madrid, el profesor Ángel Bahamonde, publicó un interesante libro sobre este tema: Madrid, 1939. La conjura del coronel Casado (Cátedra, Madrid, 2014), un análisis más centrado en los aspectos militares y en la figura de Segismundo Casado. También hace falta mencionar aquí la obra de Ángel Viñas y de Fernando Hernández Sánchez El desplome de la República (Crítica, Barcelona, 2009). Ambos libros se editaron cumpliéndose aniversarios concretos. Por el 75 aniversario del final de la Guerra civil el primero y por el 70 aniversario el segundo. Sin embargo, cuando parecía que las obras en liza marcaban casi a la perfección aquellos trágicos días finales de la Guerra civil, Paul Preston nos sorprende con una magnífico libro que los analiza pormenorizadamente. La obra de Preston recorre desde las figuras fundamentales de aquel proceso (Juan Negrín, Segismundo Casado, Julián Besteiro, Cipriano Mera, etc.), hasta el posicionamiento de las distintas organizaciones en el conflicto. Como buen conocedor de la realidad española del momento, Preston analiza los antecedentes que llevaron al final de la Guerra. Las fuertes disputas que se dieron en el seno del campo republicano marcaron la pauta de aquellas semanas. Igualmente esta obra se convierte en un estudio mucho más profundo al analizar no sólo el conflicto que surgió en la capital de la España republicana sino en otras zonas leales.

La obra de Preston tiene tres protagonistas. Por una parte Juan Negrín, presidente del Gobierno de la Segunda República, según el autor, víctima de una conjura en la que participan distintos intereses que confluyen en ideas comunes. Por otra parte, Segismundo Casado, militar leal a la República pero al mismo tiempo ambicioso y fuertemente anticomunista que pretendía acaparar un protagonismo que no le correspondía. Y por último, Julián Besteiro, una de las figuras más importantes del socialismo español. El libro de Preston es riguroso y completo. Y no es sencillo por lo complejo del tema. El final de la Guerra civil es un cúmulo de factores diversos que solo un investigador ducho en el tema puede tener en cuesta, un mapa en el que recomponer las distintas piezas para comprender que lleva a cada grupo o a cada persona a apoyar determinadas medidas. El golpe que Casado da en Madrid el 5 de marzo de 1939 tuvo distintas motivaciones tanto para los que lo apoyaron como para los que se opusieron. Porque no es lo mismo la motivación de un militar como Casado, que se veía relegado de lo que él mismo quería representar, un militar que pretendía pasar a la historia de España como quien trajo la paz en la Guerra civil, que las pretensiones de un ya viejo Besteiro que se veía como un factor de reconciliación entre los sublevados y los leales. No es lo mismo tampoco el presidente Juan Negrín, que había planteado la posibilidad de una salida dialogada en la Guerra pero siempre salvaguardando la vida de los leales, que los dirigentes del Partido Comunista de España que tenían una posición de resistencia numantina en la que en febrero de 1939 nadie ya creía. Tampoco 
fueron iguales las motivaciones que llevaron tanto a socialistas caballeristas como a una parte del anarcosindicalismo a apoyar el golpe de Casado teniendo en cuenta la gran cantidad de querellas internas que habían acumulado contra Negrín los primeros y contra los comunistas, los segundos.

Siguiendo el libro de Preston, nos damos cuenta que Negrín, como los libertarios, como los comunistas y los socialistas caballeristas no esperaban nada de Franco y los sublevados. El caso de los anarquistas es complejo. Su apoyo a Casado se debe exclusivamente a su deseo de echar del poder a los comunistas que en mayo de 1937 les habían desalojado a ellos. Pero tenían claro que frente a Franco sólo cabía la resistencia. Una resistencia en la que no creía absolutamente para nada Casado. Cuestión que se comprueba no sólo en el libro de Preston sino en las propias memorias de Cipriano Mera, el albañil anarquista que había tomado el mando del IV Cuerpo del Ejército Popular de la República. El peso del anticomunismo en un sector importante del anarquismo era más que evidente.

Por otra parte, la definición de Besteiro como «ingenuo» por parte de Preston no puede ser más acertada. El histórico dirigente ugetista, que durante la Guerra civil apenas tuvo importancia, creyó tener la llave para negociar con Franco. Esa ingenuidad que le llevó a quedarse en la capital con la entrada de las tropas franquistas y que le condujo ante un Consejo de Guerra y al presidio en Carmona falleciendo apenas un año después. Con él también se quedó Melchor Rodríguez, el «Ángel Rojo», uno de los representantes del anarquismo humanista, que salvó la vida de muchas personas y que también fue a la cárcel tras la guerra.

Pero los dos grandes protagonistas de aquellas jornadas fueron Casado, por una parte, y Negrín, por otra. Casado, a pesar de decir que pretendía una paz honrosa y salida pactada de la Guerra, pocas condiciones podía ofrecer a Franco en Burgos. Su famosa frase «La entrega se verificará en tales condiciones que no exista precedente en la historia y que será el asombro del mundo» era papel mojado teniendo en cuenta que Franco nada quería negociar ni pactar. Cuando las conversaciones de Gamonal fracasaron entre los emisarios de Casado (alguno de ellos integrante de la Quinta Columna) y los sublevados de Franco, los argumentos del coronel quedaron completamente anulados. Aquí estriba el punto de fricción entre Casado y su equipo de militares, esos apoyos circunstanciales de los que se dotó para que su golpe llegase a buen puerto. La idea de un «abrazo de Vergara» nunca se produjo,

Juan Negrín, que había tomado el poder del ejecutivo tras la crisis de mayo de 1937 , era partidario de una paz negociada desde 1938. Algo que no sólo Preston plantea sino también Gabriel Jackson en su Juan Negrín. Médico, socialista y jefe del Gobierno de la II República española (Crítica, Barcelona, 2008). Lo que el presidente del Gobierno no iba a tolerar es una rendición sin condiciones, que era la idea de Franco. Los puntos débiles de Negrín eran el escaso apoyo que contó en el seno del Frente Popular, muy dividido ya a finales de 1938, la nula comprensión del presidente de la República, Manuel Azaña, y el abandono definitivo y tácito de Francia e Inglaterra, cuando en febrero de 1939 reconocieron al gobierno de Franco.

La obra de Preston no sólo recuerda las divergencias políticas entre los distintos grupos del Frente Popular que desembocó en el golpe de marzo de 1939 sino que narra también de forma pormenoriza los enfrentamientos tanto de Cartagena como de Madrid. El primero, menos conocido para la historiografía, presentó un panorama caótico en aquellas jornadas: por una parte, unos grupos falangistas y franquistas que ven en el caos generalizado de la ciudad la oportunidad de hacerse con control; por otra, las fuerzas leales al gobierno de Negrín. Y por último, algunos republicanos no conformes con el negrisnismo que se 
sublevan contra su propio gobierno pero que combaten a los franquistas. Un ejemplo de cómo la Quinta Columna estaba organizada en esta ciudad mediterránea. La posición en Madrid fue distinta. La Quinta Columna estaba al tanto de los movimientos que Casado iba a hacer y no intervino directamente. Alguno de los militares más cercanos a Casado, como José Centaño de la Paz, eran integrantes de la Quinta Columna. Otros como Manuel Matallana tenían posiciones ambigüas. El triunfo del golpe en Madrid no se debió a los militares tibios que Casado tenía a su alrededor, sino a las fuerzas de los «casadistas» que lograron vencer las unidades leales a Negrín y que mayoritariamente eran de mandos adscritos al Partido Comunista. E1 IV Cuerpo de Ejército de Cipriano Mera fue fundamental para ello.

Tras la victoria de Casado vino la represión contra las fuerzas derrotadas y el desencanto de aquellos que esperaban que con su acción las circunstancias hubiesen discurrido por otros derroteros. Todo ello, unido a unas negociaciones imposibles, provocó el final de la Guerra y la entrada de Franco en Madrid. Lo que Preston deja claro es que la represión actuó contra todos. Si bien algún alto cargo de Casado se pudo ver beneficiado por su labor ambigua, el destino de muchos de ellos fue el presidio, el paredón o el exilio. Incluso tibios como Matallana tuvieron un periodo de prisión y nunca más volvieron a estar en el Ejército. Hay que recordar que una de las obsesiones de Casado era que el bando vencedor respetase los grados militares del Ejército republicano. Nada de eso sucedió. Otros casos fueron más llamativos. Julián Besteiro fue detenido, juzgado y condenado (se llegó a pedir la pena de muerte) a treinta años de prisión. Falleció un año después, en 1940, enfermo en la cárcel de Carmona. Cipriano Mera logró alcanzar Orán. Pero, con el inicio de la Guerra mundial, fue detenido y extraditado a España. Juzgado, fue condenado a muerte y se le conmutó la pena. Salió de prisión y continuó su lucha contra Franco hasta que se vio obligado a salir exiliado, muriendo en París en octubre de 1975. Melchor Rodríguez también fue detenido y condenado. Penó en muchas prisiones y al salir se ganó la vida como vendedor de seguros, falleciendo en Madrid en 1972. Otros como Mauro Bajatierra fueron asesinados con la llegada de las tropas rebeldes a Madrid en marzo de 1939. Feliciano Benito fue fusilado en Guadalajara en octubre de 1940. Esto demostró que haber sido «casadista» no libraba a nadie de nada.

Casado logró huir. Se estableció en Inglaterra un tiempo y luego fue a Venezuela. Aunque tuvo contacto durante algún tiempo con personalidades del exilio, su objetivo era volver a España. En 1961 regresó a España. Por la petición de una pensión fue investigado y procesado por su pasado republicano. Intentó congraciarse re-escribiendo su libro de memorias Así cayó Madrid. Tal como Preston lo muestra la versión que publicó en Londres en 1939 a la que editó en España en 1967 poco tenían que ver. Falleció en 1968.

El libro de Preston es completo, muy bien documentado y acerca un poco más a lo que fueron aquellos últimos días. Un magnífico y excelente compendio tanto de las luchas intestinas como de alguna de las personalidades que jugaron un papel fundamental en aquella historia. Si bien el libro se centra mucho más en las figuras antagónicas de Casado y Negrín, las razones de fondo y de peso que llevaron a apoyar el golpe a fuerzas como la Agrupación Socialista de Madrid (de corte caballerista) y el Movimiento Libertario Español quedan en un segundo plano. Pero eso ya de por sí podría ser una nueva obra. Quizá una idea para que uno de los mejores historiadores del momento, como Paul Preston, nos vuelva a sorprender. 